\title{
The Growth of Myxamoebae of the True Slime Mould, Didymium nigripes, in Axenic Culture
}

\author{
BY N. S. KERR \\ Department of Zoology, University of Minnesota, \\ Minneapolis 14, Minnesota, U.S.A.
}

(Received 11 March 1963)

\begin{abstract}
SUMMARY
Myxamoebae of Didymium nigripes were grown in a peptone + yeast extract +glucose broth to which formalin-killed Aerobacter aerogenes or Bacillus megaterium had been added. Either the formalin-killed bacteria or a fraction from broken bacteria was indispensable for growth. The activity of the bacteria was destroyed by heat. The supernatant fluid of sonically disrupted bacteria supported growth; the active fraction of this was non-dialysable and was precipitated by ammonium sulphate. Lysed bacterial protoplasts did not support growth. Numerous compounds were tested unsuccessfully in attempting to eliminate the bacterial factor. When glucose was omitted from the medium the initial growth rate did not change but the population began to decrease rapidly after the fifth day.
\end{abstract}

\section{INTRODUCTION}

During the life cycle of the true slime moulds several interesting morphogenetic events take place. Spores germinate to yield uninucleate myxamoebae, which are capable of differentiating into flagellated swarm cells. After a period of growth and division the myxamoebae differentiate, probably with sexual fusion, into masses of coenocytic protoplasm called plasmodia; these continue to enlarge for a time before differentiating into fruiting bodies which contain spores. Mycetozoa have usually been cultivated in the laboratory by feeding them with living bacteria or yeast. The presence of living associates makes many studies difficult, and the goal of growing these organisms on a defined medium has long attracted the attention of biologists. One of the first careful nutritional investigations was that of Cohen (1939), who devised techniques for freeing plasmodia of contaminating organisms and growing them on killed yeast. Sobels (1950) and Hok (1954) extended these studies. More recently, Daniel \& Rusch (1961) devised a defined medium for plasmodia of Physarum polycephalum.

In many ways Didymium nigripes is an ideal subject for investigation; it completes its life cycle in less than 7 days (Kerr \& Sussman, 1958), making all stages of the life cycle readily accessible. Although $D$. nigripes has been studied extensively, there is no record of previous attempts to grow this organism in axenic culture. The present investigation was designed to overcome this deficiency.

The uninucleate amoeboid stage in the life cycle was chosen for the first attempts at axenic culture. Among the advantages of using this stage is that growth is easily measured as an increase in the number of myxamoebae. Amoebae are more readily subcultured in a reproducible fashion than are plasmodia. Two of the most important 
morphogenetic events in the life cycle begin with myxamoebae: flagella formation and plasmodium formation. One reason for working with an axenic medium was to make the isolation of mutant stocks easier. The myxamoebae are presumably haploid, whereas the plasmodia may be diploid.

There are only a few reports of axenic culture of amoebae. Reich (1935) succeeded in growing Mayorella palistinensis on a peptone medium. Caillieu (1933) and Neff (1957) did likewise for a species of Acanthamoeba. Adam (1959) grew Acanthamoeba sp. and Band (1959) grew Hartmanella rhysoides on defined media. Sussman (1963) grew Polysphondylium pallidum on a medium containing lecithin and skim milk. Other small amoebae have been successfully grown in axenic culture only by including in the medium killed bacteria or a fraction isolated from bacteria. Brent (1954) could obtain axenic growth of Tetramitus rostratus only by including heat-killed bacteria in the medium. Sussman \& Bradley (1954) isolated a heat-stable protein from Aerobacter aerogenes which supported growth of amoebae of Dictyostelium discoideum.

\section{METHODS}

For most of the experiments $5 \mathrm{ml}$. cultures of myxamoebae were grown in $25 \mathrm{ml}$. Falcon plastic tissue culture flasks. During the latter part of the work $5 \mathrm{ml}$. cultures in $16 \times 150 \mathrm{~mm}$. test tubes, capped with Morton closures, were incubated on a $1 \mathrm{rev} . / \mathrm{min}$. roller drum. When $50 \mathrm{ml}$. cultures were needed spinner flasks or Erlenmeyer flasks on a gyrotatory shaker were used. All cultures were grown at $\mathbf{2 2}^{\circ}$. Growth rates and final yields were comparable in all the containers used.

An increase in number of myxamoebae was used as an index of growth. Counts were made in a Levy counting chamber with Fuchs-Rosenthal rulings, $\mathbf{0 \cdot 2} \mathbf{~ m m}$. deep. Neff, Neff \& Taylor (1958) had difficulty in freeing Acanthamoeba from the walls of the culture flask. Myxamoebae of Didymium nigripes were easily dislodged from the walls of the culture chamber by swirling or shaking the container.

Heat-stable components of the medium were autoclaved and then dispensed into individual growth containers. Sugars were autoclaved separately. Heat-labile components were sterilized by passing them through an AM-7 Polypore membrane filter.

Aerobacter aerogenes and Bacillus megaterium were killed with formalin by a modification of the procedure of Weinstein \& Jones (1956). Bacteria, grown for 2 days at $22^{\circ}$ on glucose + peptone + yeast extract agar, were harvested with water and washed once by differential centrifugation. The washed pellet was resuspended in water to give a suspension with the consistency of thick cream. Sufficient $40 \%$ formaldehyde (USP) was added to make the formaldehyde concentration $7 \%$. The formaldehyde + bacteria mixture stood at room temperature for a day, and the formaldehyde was then removed by washing the bacteria with water by centrifugation; four washes over a period of 2 days were usually sufficient. The washed formalinkilled bacteria were diluted with sterile water until the final concentration was equivalent to about $25 \mathrm{mg}$. dry weight $/ \mathrm{ml}$. The formalin-killed bacteria could be stored for several months in the refrigerator without loss of activity.

Several procedures were used to fractionate living bacteria in attempting to liberate a growth-promoting fraction. Bacteria were suspended in $\mathbf{0} \cdot \mathbf{1} \mathbf{M}$-phosphate buffer (pH 6.5) and treated for $45 \mathrm{~min}$. in a Raytheon sonicator. The disrupted bacterial suspension was centrifuged to remove the larger particles. The supernatant 
fluid was then filter-sterilized. A cooled semi-micro head on a Waring blender was also used to break the bacteria.

Penicillin-induced spheroplasts of Aerobacter aerogenes were made by using the procedure of Gebicki \& James (1960). Lysozyme-induced protoplasts of Escherichia coli were made by using procedures described by Spizizen (1962).

Purification of myxamoebae. Didymium nigripes was routinely grown in monoxenic culture on Aerobacter aerogenes. The myxomycete was freed from its bacterial associate by one of two procedures. Spores of $D$. nigripes were suspended in glucose + peptone + yeast extract broth to which 1000 units penicillin $/ \mathrm{ml}$. and $0.5 \mathrm{mg}$. streptomycin $/ \mathrm{ml}$., filter-sterilized, had been added. The spores were incubated in the antibiotic-containing medium for one day and then removed by centrifugation and used as an inoculum. Because this procedure only occasionally succeeded in freeing the spores of all contaminants, a modification of the migration technique devised by Cohen (1939) was developed. A plasmodium was subcultured to a streak of formalin-killed $A$. aerogenes on plain agar. The plasmodium migrated along the streak of bacteria, consuming them as it moved. When it approached the far end of the streak it was subcultured to plain agar, where it fruited. The resulting spores were almost always free of contaminants. Sterility tests were made frequently to check for contaminants. A drop of the culture was plated on a rich glucose + peptone + yeast extract agar similar in composition to the axenic growth medium. The plate was incubated for at least a week before being discarded. When an axenic culture was first established, it was inoculated on to and stabbed into a variety of other media to test more exhaustively for contamination.

\section{RESULTS}

Spores of Didymium nigripes, freed from contaminants as described, were placed in a $1 \%$ peptone $+1 \%$ glucose $+0.1 \%$ yeast extract $(\mathrm{w} / \mathrm{v})$ medium buffered with $0.01 \mathrm{~m}$-phosphate ( $\mathrm{pH} \mathrm{6.5}$; hereafter called PGY) to which about $500 \mu \mathrm{g}$. dry wt. $/ \mathrm{ml}$. formalin-killed Aerobacter aerogenes had been added. The myxamoebae grew and could be maintained indefinitely with periodical subculture. The one component of the medium essential for growth was the formalin-killed bacteria. When myxamoebae were subcultured to a medium without the bacteria, only a small increase in number resulted (Fig. 1). When these myxamoebae were again subcultured, there was no further growth. Myxamoebae subcultured to phosphate buffer + formalinkilled bacteria grew slowly; the growth rate was markedly improved by adding peptone or yeast extract. Best growth was obtained when all components were present. Aerobic conditions were necessary for growth.

A variety of proteins and protein digests was substituted for the peptone. Concentrations between $0 \cdot 2 \%(\mathrm{w} / \mathrm{v})$ and $2 \%$ of neopeptone, phytone, thiotone, proteose peptone, Casamino acids, gelatin, tryptone, trypticase, and tryptose all resulted in good growth. Since growth was as good on the $1 \%$ Difco Bacto-peptone as on any of the other protein digests this has been routinely included in the medium. Yeast extract, beef extract, and a variety of liver fractions were added to the $1 \%$ peptone singly and in admixtures; growth was improved by adding any one of these. Difco yeast extract $(0 \cdot 1 \%, \mathrm{w} / \mathrm{v})$ is now routinely included in the medium. Buffers ranging from $\mathrm{pH} 4$ to 9 were substituted for the $\mathrm{pH} 6.5$ phosphate. Best growth was obtained at $\mathrm{pH} \mathbf{6 \cdot 5}$. 
Effect of glucose. Adding 0.05 M-glucose to the medium did not affect the growth rate, but the final yield was greater and large populations of amoebae could be maintained in the stationary phase only when glucose was included. In its absence the population of amoebae began to decrease rapidly on the 5th day of incubation (Fig. 1). When such cultures were left undisturbed for 5-10 days, small plasmodia appeared. No plasmodia were found in cultures containing glucose. Adding filtersterilized glucose after the other components of the medium had been autoclaved did not affect this result.

Table 1. The effect of sugars on population size of myxamoebae in the stationary phase

\begin{tabular}{|c|c|c|c|c|c|c|}
\hline \multirow{3}{*}{ Sugar } & \multicolumn{4}{|c|}{$\begin{array}{l}\text { No. of myxamoebae } / \mathrm{ml} \text {. expressed as } \% \text { of } \\
\text { number of myxamoebae } / \mathrm{ml} \text {. at } 7 \text { days } \\
\text { grown in } 0.05 \mathrm{M} \text { glucose }\end{array}$} & \multicolumn{2}{|c|}{$\begin{array}{l}\text { Ratio of no. of } \\
\text { myxamoebae at } 7 \text { days } \\
\text { to no. at } 10 \text { days }\end{array}$} \\
\hline & \multicolumn{2}{|c|}{$0.01 \mathrm{M}$} & \multicolumn{2}{|c|}{$0.05 \mathrm{M}$} & \multirow[t]{2}{*}{$0.01 \mathrm{M}$} & \multirow[t]{2}{*}{$0.05 \mathrm{M}$} \\
\hline & 7 days & 10 days & 7 days & 10 days & & \\
\hline None & (31) & (18) & . & . & $(1 \cdot 68)$ & . \\
\hline D-Glucose & 65 & 60 & 100 & 106 & $1 \cdot 10$ & 0.95 \\
\hline D-Mannose & 31 & 47 & 104 & 136 & 0.81 & $0 \cdot 76$ \\
\hline D-Galactose & 58 & 52 & 90 & 72 & $1 \cdot 13$ & $1 \cdot 24$ \\
\hline D-Fructose & 43 & 21 & 35 & 21 & $2 \cdot 20$ & $1 \cdot 65$ \\
\hline Maltose & 45 & 33 & 55 & 55 & $1 \cdot 38$ & $1 \cdot 00$ \\
\hline Lactose & 49 & 42 & 75 & 51 & $1 \cdot 17$ & $1 \cdot 48$ \\
\hline Sucrose & 31 & 28 & 51 & 32 & $1 \cdot 11$ & $\mathbf{I} \cdot 56$ \\
\hline L-Arabinose & 31 & 10 & 17 & 6 & 3.00 & $2 \cdot 88$ \\
\hline D-Xylose & 44 & 27 & 44 & 22 & $1 \cdot 62$ & $2 \cdot 00$ \\
\hline Raffinose & 31 & 30 & 65 & 49 & $1 \cdot 14$ & $1 \cdot 31$ \\
\hline D-Ribose & 33 & 10 & 17 & 6 & $\mathbf{3} \cdot \mathbf{3 3}$ & $\mathbf{2} \cdot \mathbf{5 2}$ \\
\hline
\end{tabular}

Each value represents the mean of three experiments.

A number of other sugars were tested to see whether they would mimic the effect of glucose (Table 1). Counts were made of each culture after 3, 7, and 10 days. After 3 days the myxamoebae were nearing the end of logarithmic growth (Fig. 1), but there was no significant difference between the cultures at this time. After 7 days, only galactose and mannose permitted yields comparable to those obtained with glucose. Mannose, galactose, lactose, sucrose, and raffinose were the only sugars able to maintain the population at a given value between 7 and 10 days. Only when mannose or glucose was present did the population continue to increase up to the 10th day. None of the sugars tested supported growth in the absence of formalinkilled bacteria.

Bacterial preparations tested for growth promotion. When different amounts of formalin-killed Aerobacter aerogenes were added to the PGY medium, the growth rate was independent of bacterial concentration (Fig. 1). At $22^{\circ}$ the generation time was about $11 \mathrm{hr}$., as compared with a generation time of $4.5 \mathrm{hr}$. when the amoebae were grown on agar with living $A$. aerogenes (Kerr, 1961). The maximum number of amoebae $/ \mathrm{ml}$. was proportional to the amount of bacteria added. Similar results were obtained with formalin-killed Bacillus megaterium (Fig. 2), with a generation time of about $13 \mathrm{hr}$. The growth-supporting activity of formalin-killed bacteria was heat-labile. Formalin-killed $A$. aerogenes were added to $5 \mathrm{ml}$. tubes of PGY and 
heated at various temperatures for $15 \mathrm{~min}$. in a water bath. The activity was decreased by about one half by heating to $80^{\circ}$ and completely destroyed at $90^{\circ}$.

Penicillin-induced spheroplasts of Aerobacter aerogenes were lysed in $0 \cdot 1 \mathrm{M}$ -

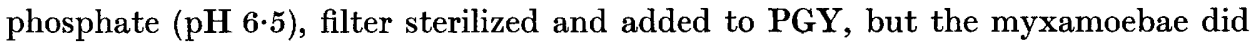
not grow. Nor were washed, lysed, lysozyme protoplasts of Escherichia coli able to support growth. The recipe for producing lysozyme protoplasts was modified by omitting sucrose. Under these conditions, the bacteria were lysed instead of being

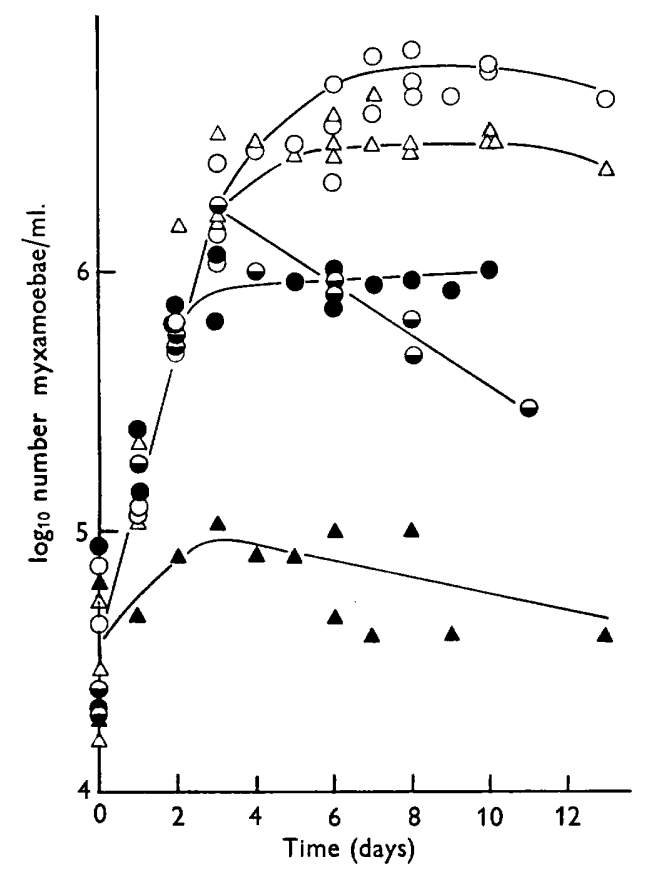

Fig. 1

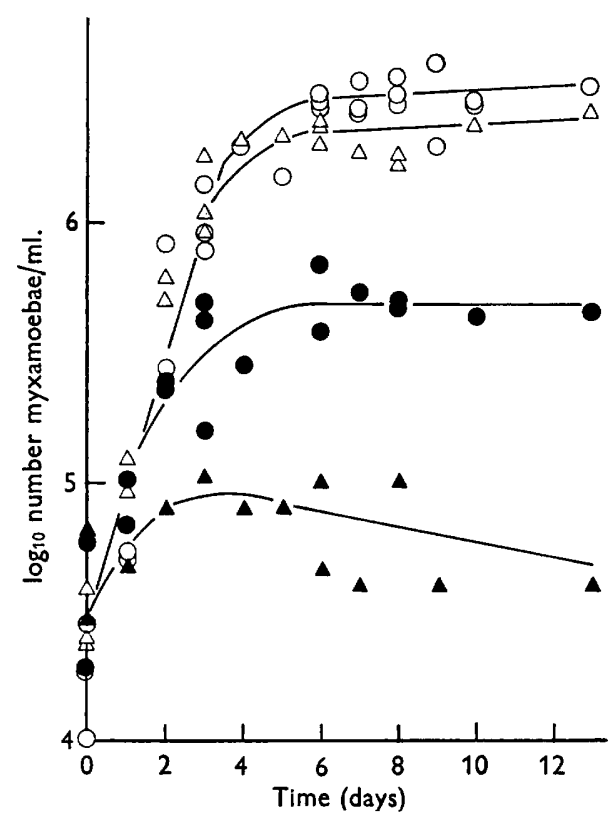

Fig. 2

Fig. 1. The growth of Didymium nigripes on formalin-killed Aerobacter aerogenes.

Fig. 2. The growth of Didymium nigripes on formalin-killed Bacillus megaterium.

$O=$ PGY medium $+1000 \mu \mathrm{g}$. dry wt. bacteria $/ \mathrm{ml}$. $\Delta=$ PGY medium $+500 \mu \mathrm{g}$. dry wt. bacteria $/ \mathrm{ml}$; $\ominus=$ PGY medium $+50 \mu \mathrm{g}$. dry wt. bacteria $/ \mathrm{ml}$.; $\ominus=\mathbf{P Y}$ (no glucose) medium $+500 \mu \mathrm{g}$. dry wt. bacteria $/ \mathrm{ml}$.; $\mathbf{A}=$ PGY medium alone.

converted to protoplasts. Sufficient $\mathrm{CaCl}_{2}$ was then added to bind with the ethylenediamine tetra-acetate necessary for lysis, but this mixture did not support growth of myxamoebae. All of the above preparations permitted growth when formalinkilled bacteria were added to them, showing that they were not toxic.

When Aerobacter aerogenes was treated exhaustively in a sonic-oscillator or in a Waring blender, the filter-sterilized supernatant fluid supported growth with a generation time of $24 \mathrm{hr}$. When dialysed, the activity remained in the dialysis residue. The active fraction was precipitated by ammonium sulphate.

Aerobacter aerogenes were dried with solid $\mathrm{CO}_{2}+$ acetone and subsequently sterilized by formalin treatment. The acetone-dried bacteria supported growth of myxamoebae but the dried acetone extract was inactive. 
Attempts to replace the bacterial fraction. Several media, reported to support axenic growth of other amoeboid organisms, were tested. The medium devised by Daniel \& Rusch (1961) for plasmodia of Physarum polycephalum and that reported by Sussman (1963) to support growth of Polysphondylium pallidum were both inactive. Tissue culture media, such as medium 199 and Scherer's medium (with or without serum) did not support growth. Any of the above supported growth after the addition of formalin-killed bacteria.

Supernatant fluids of axenic cultures of Acanthamoeba sp. and Tetrahymena pyriformis were tested to see whether these organisms produced a diffusible metabolite that would replace the bacterial factor. No positive results were obtained.

Different compounds were added to PGY medium to see whether they would replace the formalin-killed bacteria. Ribonucleic acid, deoxyribonucleic acid, serum albumin, embryo extracts, liver fractions, haemin, haematin, Eagle vitamin mix + vitamin $B_{12}$, bacitracin, Tween 20 , Tween 80 , whole egg, lecithin, $\beta$-sitosterol, menadione sulphate and lysine were among the compounds tested. None supported growth.

That lysed protoplasts could not support growth, whereas bacteria broken by sonic treatment did, suggested that the active component might be in the bacterial cell wall or capsule. Several commercially available constituents of bacterial cell walls, including L-rhamnose, D-arabinose, glucuronic acid lactone, D-alanine, D-glutamic acid and polygalacturonic acid were tested singly and in mixtures. No growth resulted in any case.

\section{DISCUSSION}

All attempts to eliminate bacteria from the culture medium which supported the growth of Didymium nigripes failed. The bacterial extract or formalin-killed bacteria might serve one of three functions. First, the bacteria might inactivate, possibly by absorption, a toxic material in the medium. This seems unlikely, but, if true, one would hardly expect the bacterial activity to be heat-labile. Furthermore, growth would not be proportional to bacterial concentration. Rather, little or no growth would occur until a certain amount of bacteria had been added and growth might then be expected to be maximal. Neither would we expect to observe one or two divisions when amoebae grown on formalin-killed bacteria were subcultured to medium without bacteria. A second possible function of the bacteria might be to stimulate the formation of food vacuoles by amoebae. Although this possibility cannot be ruled out, it seems unlikely that the requirement would be so specific. Pinocytosis, a process similar to food vacuole formation, is induced by a variety of salts and proteins. The third and most likely possibility is that the bacteria supply one or more essential metabolites. Because washed bacterial protoplasts did not support growth, the active material may be located either in the capsule or the cell wall of the bacteria. Active material is found in more than one family of bacteria but not in yeasts. It exhibits characteristics of a protein or mucopolysaccharide, being heat-labile and non-dialysable. Alternatively, it might be tightly bound to such a macromolecule. The polypeptide isolated by Sussman \& Bradley (1954), necessary for growth of Dictyostelium discoideum, differs from the present factor in that the former was stable to heat at neutral $\mathrm{pH}$ values.

The effect of glucose is interesting in that it had no effect on the growth rate of the myxamoebae. However, in its absence the size of the population underwent a 
precipitous decline, with plasmodia occasionally forming afterwards. The effect was restricted to optical isomers of glucose and to certain disaccharides containing glucose. Kerr \& Sussman (1958) noted that adding high concentrations of glucose to the agar on which myxamoebae were growing in monoxenic culture with Aerobacter aerogenes inhibited plasmodium formation. The plasmodium formation spreading technique (Kerr, 1961) was tried with axenic myxamoebae grown in the presence or absence of glucose; in neither case were plasmodial clones formed. The possibility that the axenic culture had selected a plasmodia-less strain (Kerr, 1959) was tested by subculturing axenically-grown myxamoebae to agar with living bacteria. These myxamoebae formed plasmodia normally. Hence, if in the absence of glucose plasmodia are suddenly forming, their viability in liquid culture on killed bacteria must be extremely low.

This study was begun to see whether a defined medium could be devised, making possible the selection of auxotrophic mutants for genetic studies. To date this goal has not been realized. Even if the bacterial fraction cannot be eliminated, it can be purified and characterized, making it possible to select nutritional mutants for other components of the medium. Even in its present crude form with formalin-killed bacteria, the axenic medium has opened the possibility of selecting mutants resistant to a variety of drugs and antibiotics without first selecting resistant strains of bacteria. This is now being attempted. The axenic culture will also make metabolic studies practicable. For example, it will now be possible to compare respiratory rates and changes in amount of a variety of enzymes and substrates in different stages of the life cycle.

This work was supported by grant No. NSF-G17740 from the National Science Foundation, U.S.A. I acknowledge the able technical assistance of Sharon A. Munger.

\section{REFERENCES}

Adam, K. M. G. (1959). The growth of Acanthamoeba sp. in a chemically defined medium. J. gen. Microbiol. $21,519$.

BAND, R. N. (1959). Nutritional and related biological studies on the free-living soil amoeba, Hartmanella rhysodes. J. gen. Microbiol. 21, 80.

Brent, M. M. (1954). Nutritional studies on the amoebo-flagellate, Tetramitus rostratus. Biol. Bull., Woods Hole, 106, 269.

Cailleau, R. (1933). Culture d'Acanthamoeba castellanii en milieu liquide. C.R. Soc. Biol., Paris, 113, 990.

Cohen, A. L. (1939). Nutrition of the myxomycetes. I. Pure culture and two-membered culture of myxomycete plasmodia. Bot. Gaz. 101, 243.

Daniel, J. W. \& Rusch, H. P. (1961). The pure culture of Physarum polycephalum on a partially defined soluble medium. J. gen. Microbiol. 25, 47.

GEBICKI, J. M. \& JAMES, A. M. (1960). The preparation and properties of spheroplasts of Aerobacter aerogenes. J. gen. Microbiol. 23, 9.

Hoк, K. A. (1954). Studies of the nutrition of myxomycete plasmodia. Amer. J. Bot. 41,792 .

Kerr, N. S. \& Sussman, M. (1958). Clonal development of the true slime mould, Didymium nigripes. J. gen. Microbiol. 19, 173.

Kerr, N. S. (1959). Actidione-resistant mutants of Didymium nigripes. J. Protozool. 6, suppl., 16.

Kerr, N. S. (1961). A study of plasmodium formation by the true slime mold, Didymium nigripes. Exp. Cell Res. 23, 603. 
NEFF, R. J. (1957). Purification, axenic cultivation, and description of a soil amoeba, Acanthamoeba sp. J. Protozool. 4, 176.

Neff, R. J., NefF, R. H. \& TAYlor, R. E. (1958). The nutrition and metabolism of a soil amoeba, Acanthamoeba sp. Physiol. Zool. 31, 73.

REICH, K. (1935). The cultivation of a sterile amoeba on media without solid food. J. exp. Zool. 69, 497.

Sobels, J. C. (1950). Nutrition de quelques myxomycètes en cultures pures et associées et leurs propriétés antibiotiques. Antonie van Leeureenhoek, 16, 123.

Spizizen, J. (1962). Preparation and use of protoplasts. In Methods in Enzymology. Ed. by S. P. Colowick and N. O. Kaplan, 5, 122. New York: Academic Press, Inc.

Sussman, M. \& Bradley, S. G. (1954). A protein growth factor of bacterial origin required by the cellular slime molds. Arch. Biochem. Biophys. 51, 428.

Sussman, M. (1963). Growth of the cellular slime mold, Polysphondylium pallidum in a simple nutrient medium. Science, 139, 338.

Weinstein, P. P. \& Jones, M. F. (1956). The in vitro cultivation of Nippostrongylus muris to the adult stage. J. Parasitol. 42, 215. 